\title{
IMPLEMENTING SUSTAINABILITY: ARE UNIVERSITIES LEADING THE WAY?
}

Linda Brennan, RMIT University, Australia

Wayne Binney, Victoria University, Australia

\begin{abstract}
This paper argues for a systematic consideration of environmental sustainability from a behaviour change perspective. As there are so many approaches to 'sustainability' that there are easy excuses for those unwilling to be inconvenienced. It is our contention that environmental sustainability will not simply occur by changing attitudes. Behaviour change theory suggests that for change to occur whether it is at a societal, group and individual level individuals require a code of conduct for the desired behaviour. This paper discusses the survey results from a study of university web pages to ascertain the level of development of guidelines to enable ethical-decision-making for this micro community. It is found that very few universities are providing the effective communication about expected behaviours for this influential community.
\end{abstract}

References available upon request 